\title{
Outcrossing rate and inbreeding depression in the herbaceous autotetraploid, Campanula americana
}

\author{
LF Galloway $^{1}$, JR Etterson ${ }^{1}$ and JL Hamrick ${ }^{2}$ \\ ${ }^{1}$ Department of Biology, University of Virginia, Charlottesville, VA 22904-4328, USA; ${ }^{2}$ Departments of Plant Biology and Genetics, \\ University of Georgia, Athens, GA 30602, USA
}

\begin{abstract}
Polyploidy in angiosperms is frequently associated with an increase in self-compatibility. Self-fertilization can enhance polyploid establishment, and theory predicts reduced inbreeding depression in polyploids relative to diploids. Therefore, we may expect mating systems that promote selffertilization or mixed-mating in polyploid species. However, few studies have measured polyploid mating systems and inbreeding depression. We report the outcrossing rate and inbreeding depression for Campanula americana, a selfcompatible protandrous herb. Allozyme genotypes suggest that $C$. americana is an autotetraploid with tetrasomic inheritance. We found that the multilocus outcrossing rate, $t_{\mathrm{m}}=0.938$, did not differ from unity. This result was unexpected since previous work demonstrated that pollinators frequently move from male- to female-phase flowers on the same plant, that is, geitonogamy. Self and outcross
\end{abstract}

pollinations were conducted for three populations. Offspring were germinated in controlled conditions and grown to maturity in pots in nature. Inbreeding depression was not significant for most seed and germination characters. However, all later life traits except flowering date differed between inbred and outcrossed individuals resulting in a $26 \%$ reduction in cumulative fitness for inbred plants. Limited early- and moderate later-life inbreeding depression suggest that it is buffered by the higher levels of heterozygosity found in an autotetraploid. $C$. americana appears to have a flexible mating system where within flower protandry and/or cryptic self-incompatibility result in a high outcrossing rate when pollinators are abundant, but self-compatibility and limited inbreeding depression maintain reproductive success when mates are limited.

Heredity (2003) 90, 308-315. doi:10.1038/sj.hdy.6800242

Keywords: outcrossing rate; inbreeding depression; autopolyploid; polyploid; mating system

\section{Introduction}

Polyploidy in angiosperms is frequently associated with increased self-compatibility. Chromosome doubling often produces new allelic interactions in pollen that lead to a breakdown of self-incompatibility (de Nettancourt, 2000). For example in the genus Campanula, diploid C. persicifolia are self-incompatible while tetraploid individuals are self-compatible (Gairdner, 1926). Increased self-compatibility is important for the establishment of novel polyploids. When a polyploid first arises, its gametes have twice the chromosome number of other individuals in the population. Backcrossing to diploid individuals results in low crossing success and offspring with a high frequency of sterility (Burton and Husband, 2000). In contrast, self-fertilization provides a mechanism for mating within a ploidy level and consequently results in fertile offspring. In this manner, self-compatibility allows novel polyploid individuals to circumvent the fitness disadvantage of being a minority cytotype, and polyploids that are self-compatible are more likely to become established. Therefore, although self-compatibility is a frequent byproduct of polyploidy, it can play a crucial role in the establishment of novel polyploids.

Correspondence: LF Galloway, Department of Biology, University of Virginia, Charlottesville, VA 22904-4328, USA.

E-mail: lgalloway@Virginia.edu
Changes in compatibility associated with polyploidy may influence the mating system. A predominately selfmating system will increase the probability of polyploid establishment. Therefore, morphological and genetic features that enhance self-fertilization may be favored by selection. For example, higher rates of selfing are found where tetraploid and diploid populations of the same species are sympatric than where they are allopatric (Petit et al, 1997). Support for this hypothesis is mixed and in part depends on whether polyploids are derived from within-species chromosome doubling (autopolyploid) or chromosome doubling in interspecific hybrids (allopolyploid). The majority of hermaphroditic autopolyploid species have mixed mating systems with intermediate or high outcrossing rates (MacDonald and Lieffers, 1991; Husband and Schemske, 1997; Petit et al, 1997; Inoue et al, 1998; but see Murawski et al, 1994). In contrast, selfing is more prevalent in allopolyploids (Belaoussoff and Shore, 1995; Johnston and Schoen, 1996; Cook and Soltis, 1999).

After polyploid establishment, the selective value of self-fertilization depends on the level of inbreeding depression. Inbreeding depression because of the expression of deleterious recessive or partially recessive alleles in the homozygous form is expected in selfed progeny of polyploids. Like diploids, deleterious recessive alleles expressed following inbreeding will be removed by selection (Lande and Schemske, 1985). However, the creation of fully homozygous genotypes 
proceeds more slowly in polyploid species than in diploids (Bever and Felber, 1992). This should lead to a reduction in inbreeding depression following a generation of self-fertilization in a polyploid relative to a diploid. A study of Epilobium angustifolium found less inbreeding depression in tetraploid than in diploid populations, supporting this expectation (Husband and Schemske, 1997). The reduction of inbreeding depression associated with increased self-compatibility in polyploid species suggests mating systems that promote self-fertilization or mixed-mating may be common.

In contrast with these theoretical expectations, inbreeding depression in autopolyploids has been demonstrated to be greater than predicted (Busbice and Wilsie, 1966). At present, there are too little data to evaluate whether these predictions are robust. There are few studies of polyploid species for which we have both an estimate of outcrossing rate and of inbreeding depression (Belaoussoff and Shore, 1995; Johnston and Schoen, 1996; Husband and Schemske, 1997; Dudash and Fenster, 2001). Of these, only Husband and Schemske (1997) consider an autopolyploid. The consequences of inbreeding are expected to differ between autopolyploids and allopolyploids (Bever and Felber, 1992). Autopolyploids typically display polysomic inheritance where more than two homologous chromosomes pair at meiosis. Polysomic inheritance can result in double reduction, the production of gametes with both copies of a single parental allele. Double reduction is expected to facilitate purging and hence reduce inbreeding depression in self-fertilizing species (Butruille and Boiteux, 2000). More studies are needed to evaluate the predicted relation between mating system and inbreeding depression in polyploid species, and in particular autopolyploids.

In this paper, we report on the mating system and inbreeding depression for C. americana, an autotetraploid herb. Flowers are protandrous and insect pollinated, suggesting a predominately outcrossing mating system. However, plants are self-compatible and pollinators frequently move among flowers within individuals (Galloway et al, 2002). As a consequence a mixed mating system may result. We estimate the extent of selffertilization using allozymes. We also evaluate levels of inbreeding depression for three populations. We then interpret the results in the context of theory developed to predict mating system evolution in polyploids.

\section{Materials and methods}

\section{Study species}

Campanula americana (Campanulaceae) L. (=Campanulastrum americana Small) is a monocarpic insectpollinated herb. It flowers from mid-July to late-August. Primary pollinators are bumblebees foraging for nectar and halictids collecting pollen (Galloway et al, 2002). Flowers are self-compatible but protandrous. Pollinators visit frequently and as a result the male phase is brief, with most pollen removed within $3 \mathrm{~h}$ of anthesis (Evanhoe and Galloway, 2002). Remaining pollen can be easily quantified, because prior to anthesis the pollen is deposited on pollen collecting hairs on the outer surface of the style where its presence can be visually assessed throughout the male phase. Following removal of all pollen, the flower is functionally neuter until the stigmatic lobes open the next day. Saturation of the stigma with pollen typically occurs $4-6 \mathrm{~h}$, after the onset of the female phase (Evanhoe and Galloway, 2002). However, flowers remain in female phase for 1-2 days. Between 1 and 90 flowers may be open at the same time (Galloway et al, 2002). Geitonogamous selfing may occur when pollinators visit a female-phase flower following a male-phase flower on the same plant.

The $C$. americana populations used in this study are tetraploid. Preliminary counts indicate that the chromosome number is likely $n=29$, reported by Gadella (1964, Etterson, personal observation). Allozyme electrophoresis data presented here support the conclusion that these populations are tetraploid.

\section{Outcrossing rate}

Seeds were collected by maternal plant from a natural population (Mtn700) of C. americana located $3.6 \mathrm{~km}$ from the Mountain Lake Biological Station (MLBS) in Giles Co., VA, USA. Approximately 50 seeds were haphazardly sampled across fruits from 25 randomly selected maternal plants. Seeds were germinated under nearoptimal conditions in a growth chamber $\left(23^{\circ} \mathrm{C}\right.$ day $/ 14^{\circ} \mathrm{C}$ night, $12 \mathrm{~h}$ days) in plug trays filled with MetroMix 200 at the University of Virginia. After 4 weeks of germination, 25 seedlings from each of 20 maternal plants were transplanted into pots filled with 1:5 perlite and ProMix BX. To avoid observer bias during seedling selection, the first 25 seedlings in the tray were chosen regardless of size or apparent vigor. Seedlings were grown in the greenhouse, fertilized bimonthly, and watered as necessary for 70 days.

Starch-gel electrophoresis was conducted on 480 seedlings from 20 maternal families at the University of Georgia. As a result of accidental damage and seedling mortality, family size was not fully balanced (four families, 25 reps; 13 families, 24 reps; two families, 23 reps; one family, 22 reps). Four to five rosette leaves from each individual were ground in the extraction buffer of Wendel and Parks (1982). Wicks saturated with this extract were stored $\left(-70^{\circ} \mathrm{C}\right)$ until needed for starch-gel electrophoresis.

Six enzyme systems expressing 11 polymorphic loci were assayed. Two enzyme systems, aspartate aminotransferase (Aat, two loci) and uridine diphosphatase (Upgg, two loci), did not provide adequate resolution to score band intensity, although heterozygous and homozygous individuals could be distinguished. Since there are four alleles segregating at a locus in autotetraploid species, it is necessary to score band intensity to determine the genotype. Thus, four enzyme systems with seven loci were analyzed for the estimation of the outcrossing rate. Enzyme systems and locus designations are as follows: triosephosphate isomerase (Tpi1, Tpi2, Tpi3), diaphorase (Dia1), malate dehydrogenase (Mdh1, $M d h 2)$, 6-phosphogluconate dehydrogenase (6-Pgd1). Buffer systems and staining recipes are from Soltis et al (1983). Aat, Dia, and Tpi were resolved using buffer system 8 (modified) run for $3 \mathrm{~h} 15 \mathrm{~min}$ (200 V $50 \mathrm{~mA}$ for $30 \mathrm{~min}$; $250 \mathrm{~V}$ for $30 \mathrm{~min}$; $300 \mathrm{~V}$ for the remaining time). $M d h$, 6-Pgd, and Upgg were resolved using buffer system 4 run for $4 \mathrm{~h} 30 \mathrm{~min}(50 \mathrm{~mA} 200 \mathrm{~V})$. 
Inbreeding depression

Inbreeding depression was measured for three populations of C. americana. Seeds were collected from haphazardly selected individuals in two high elevation populations (Mtn613 and Mtn700; $1.3 \mathrm{~km}$ apart, $1143 \mathrm{~m}$ ) and one low elevation population (River; $9 \mathrm{~km}$ from the first two, $488 \mathrm{~m}$ ).

Self and outcross progeny were produced on plants from the Mtn613 and River populations in the greenhouse. Field-collected seeds were germinated in a growth chamber (see above) and cold stratified for 6 weeks $\left(5^{\circ} \mathrm{C}\right)$ to induce flowering. Following vernalization, individuals were moved to a greenhouse and supplemental lights increased day length to $16 \mathrm{~h}$. Plants were watered as needed and fertilized every 2 weeks (20:20:20 NPK). Once most of the plants had started flowering, 14 plants from the Mtn613 population and 16 from the River population were selected for experimental pollinations. Buds were emasculated prior to anthesis and when the stigmatic lobes opened, flowers were either crossed with pollen from the same plant ('self') or from two random pollen donors from the same population ('outcross'). Outcross donors were selected at random from a larger pool of plants. A total of 39 donors were used for Mtn613 and 67 for the River population. Crossing treatments were alternated and each was replicated five times on each individual. The resulting fruits were harvested and seeds counted.

Self and outcross progeny for Mtn700 were produced in the natural population. A total of 22 individuals located along a transect spanning the population were selected prior to flowering. To emasculate flowers, we took advantage of the almost complete removal of pollen by visiting insects (see above). Pollen-free malephase flowers were bagged with fine mesh. Pollen donors were also covered to prevent pollen removal. We pollinated bagged flowers after the stigmatic lobes opened. In all, 10 flowers on each plant were crossed with pollen from the same plant ('self') and 10 more with pollen from two random plants ('outcross'). Mesh bags were replaced after pollination and removed the next afternoon when flower wilt indicated successful pollination. Fruits were collected when ripe and seeds counted.

Seeds were individually weighed and germinated under controlled conditions. For the Mtn613 and River populations, 15 self and 15 outcross seeds for each plant were germinated and a subset of nine seeds were individually weighed. Since seed production was poor in some individuals, a total of 363 seeds were germinated (57 fewer than the full design) for population Mt613, and 463 for the River population (17 fewer than the full design). However, seeds were equally divided between pollination treatments. For population Mt700, 10 seeds were selected from each treatment for each plant (440 seeds) and half were individually weighed. Seeds were germinated in a fully randomized design in a growth chamber (see above). Those from Mt613 and River were germinated together with each seed placed on moist filter paper in an individual well of a tissue culture plate. Seeds from Mtn700 were germinated the following year by placing them individually on the surface of soil-filled $1.5 \mathrm{ml}$ microcentrifuge tubes. The germination protocol was changed between years to ease maintaining constant moisture levels. Seeds were kept moist and scored as germinated when the cotyledons had separated. Germination was monitored daily for 50 days.

Seedlings were vernalized to stimulate flowering and then grown outdoors under near-natural conditions. Seedlings were transplanted into plug trays and coldstratified for 6 weeks at $5^{\circ} \mathrm{C}$. Following vernalization, the number of leaves and the length of the longest leaf were measured. Leaf number and leaf length were highly correlated in all populations $(R=0.68-0.80)$, therefore results are only reported for leaf length. In addition, we recorded individuals that died during vernalization (usually at the cotyledon stage). Plants were then brought to MLBS and individually transplanted into $4 \times 14 \mathrm{~cm}^{2}$ tubular pots ('containers') in a 2:1 mix of Promix:topsoil. Pots were placed in a partially shaded clearing with a light regime similar to their home site to mimic natural conditions. Plants were watered as needed and fertilized every 2 weeks (20:20:20 NPK). Plants from Mtn613 and River were returned to the greenhouse just prior to flowering because of time constraints. The date of flowering was recorded. At the end of the season, plants were harvested and aboveground biomass and flower production were quantified. Since the inferior ovaries of flowers are persistent, it is possible to assess lifetime flower production. Cumulative fitness was estimated by the number of flowers produced; individuals that did not germinate or survive to flowering were assigned a fitness of zero (equivalent to a multiplicative fitness function, eg Dudash and Fenster, 2001).

\section{Statistical analysis}

\section{Outcrossing rate}

Allozyme data were analyzed with a multiallelic extension of Ritland's (1990) TETRAT programs, MLTET. Maternal genotypes were inferred from progeny arrays. Standard errors of the estimates were based on 100 bootstraps with replacement from the original data set with 'family' as the unit of resampling. Ovule and pollen allele frequencies were constrained to be equal. Multilocus and average single-locus outcrossing estimates and the single-locus inbreeding coefficient of maternal parents are presented.

The primary outcrossing rate, the proportion of outcrossed progeny at the time of fertilization, may be less than the measured outcrossing rate if inbreeding depression has removed individuals from the measured population. The primary selfing rate was calculated using

$$
s_{\mathrm{p}}=s_{\mathrm{m}} /\left(1-\delta+s_{\mathrm{m}} \delta\right)
$$

where $s_{\mathrm{p}}$ is the primary selfing rate, $s_{\mathrm{m}}$ is the measured selfing rate, and $\delta$ is the inbreeding depression value for seed production and germination combined (see $\delta$ below; Maki, 1993). Survivorship was not measured at a fine enough scale in the inbreeding depression study to include in the estimate. The primary outcrossing rate $\left(t_{\mathrm{p}}\right)$ is $1-s_{\mathrm{p}}$.

\section{Inbreeding depression}

The influence of the crossing treatment on offspring traits was analyzed with a mixed model analysis of variance. The year the experiment was conducted was included as a blocking factor (fixed effect). Population was nested 
within year (fixed effect) and maternal plant nested within population and year (random effect). Since only a single population was evaluated the second year, population effects are confounded with year effects. Crossing treatment was included as a fixed effect and interactions between all other factors and crossing treatment were tested. Interactions with crossing treatment test whether the effects of selfing (ie inbreeding depression) vary between years, populations, or among maternal plants in each population. The influence of crossing treatment was evaluated for the number of seeds per fruit, individual seed mass, the number of days to germination, rosette leaf size, the number of days to flowering, final biomass, and number of flowers produced on reproductive individuals. Days to germination was natural-log transformed, and flower number squareroot transformed to meet ANOVA assumptions.

Percent germination, percent survivorship from germination to flowering, and percent flowering were calculated for each crossing treatment for each maternal plant. Percentages were arcsine square-root transformed for analysis. Individual estimates of cumulative fitness did not meet the assumptions of ANOVA (too many zeros) and therefore were averaged across all individuals within each crossing treatment for each plant. These traits were analyzed using the ANOVA model above without the plant-by-crossing treatment interaction.

Reduction in fitness of selfed progeny relative to outcrossed progeny was estimated for each trait by $\delta$, the coefficient of inbreeding depression. $\delta$ is equal to one minus the ratio of the fitness of self offspring to outcross offspring $\left(1-\left[w_{\mathrm{s}} / w_{\mathrm{o}}\right]\right)$, and was calculated for each family in each population. A $t$-test was used to determine if $\delta$ differed significantly from 0 . Since there was little variation in the effect of crossing treatment among populations (see below), values of $\delta$ were pooled across populations for the analysis. $P$-values from $t$-tests were adjusted with a sequential Bonferroni test.

\section{Results}

\section{Outcrossing rate}

The pattern of genotypic diversity in C. americana suggests an autotetraploid rather than an allotetraploid origin for this species. We found no evidence of fixed heterozygotes as would be expected in an allotetraploid species. Furthermore, two of seven enzyme systems (Tpi1, Dia1) showed evidence for the tetrasomic pattern of inheritance characteristic of autotetraploids. In these cases, the collection of genotypes present within a family group could only have been produced if maternal alleles were segregating independently into gametes. Tetrasomic inheritance may not have been detected at the three remaining loci because of low allelic diversity at these sites (Table 1). Alternatively, these sites may be located near the centromere and thus experience lower rates of crossingover making the tetrasomic pattern of inheritance more difficult to detect.

Both the multilocus and average single-locus outcrossing rates were high indicating that little selffertilization occurs in this population, $t_{\mathrm{m}}=0.938$ (SE $0.036), t_{\mathrm{s}}=0.839$ (SE 0.054). The inbreeding coefficient was correspondingly low, $F=0.276$ (SE 0.172). In addition, the low biparental inbreeding rate, $t_{\mathrm{m}}-t_{\mathrm{s}}=0.099$ (SE
Table 1 Estimated allele frequencies and standard errors for seven loci scored to estimate outcrossing rate in C. americana

\begin{tabular}{lcccc}
\hline \multirow{2}{*}{ Locus } & \multicolumn{4}{c}{ Frequencies } \\
\cline { 2 - 5 } & Allele 1 & Allele 2 & Allele 3 & Allele 4 \\
\hline Tpi1 & $0.135(0.018)$ & $0.037(0.014)$ & $0.704(0.022)$ & $0.157(0.017)$ \\
Tpi2 & $0.169(0.027)$ & $0.831(0.027)$ & & \\
Tpi3 & $0.894(0.020)$ & $0.106(0.020)$ & & \\
Dia1 & $0.174(0.019)$ & $0.665(0.023)$ & $0.127(0.022)$ & \\
Mdh1 & $0.154(0.019)$ & $0.846(0.019)$ & & \\
Mdh2 & $0.788(0.028)$ & $0.212(0.028)$ & & \\
6-Pgd & $0.011(0.012)$ & $0.973(0.014)$ & $0.002(0.010)$ & \\
\hline
\end{tabular}

0.027), indicates that little inbreeding occurs because of mating between related individuals.

The primary outcrossing rate was very similar to the measured outcrossing rate. The combined inbreeding depression of seed production and germination is $\delta=0.076$ for the Mtn700 population. With $s_{\mathrm{m}}=0.062$ (where $s_{\mathrm{m}}=1-t_{\mathrm{m}}$ ), the $s_{\mathrm{p}}=0.067$. The small difference between the measured and the primary selfing rate is because of low inbreeding depression for early life cycle traits. As expected, the corresponding primary outcrossing rate, 0.933, is slightly less than the measured outcrossing rate.

\section{Inbreeding depression}

Crossing treatment did not influence fruit production. Of the 285 pollinations conducted in the greenhouse, $12.3 \%$ did not produce fruits. The frequency of fruit production did not differ between the crossing treatments for either the Mtn613 $\left(\chi^{2}=0.08, \mathrm{df}=1, P=0.78\right)$ or the River $\left(\chi^{2}=1.31, \mathrm{df}=1, P=0.25\right)$ populations. Only $2.1 \%$ of pollinations on field plants (Mtn700) did not result in fruit and these also did not differ between the pollination treatments $\left(\chi^{2}=0.13, \mathrm{df}=1, P=0.72\right)$.

Significant differences between self and outcross progeny were found for most of the characters studied. On average, self-matings produced fewer seeds that tended to be lighter than seeds of outcross matings (Tables 2 and 3). While the same percentage of inbred seeds germinated as outcross seeds, they did so more slowly. Inbreeding had a substantial effect on plant size, reducing rosette leaf length and biomass at harvest (Tables 2 and 3). Fewer inbred individuals survived to bolting and a smaller percentage of those that survived flowered. While the number of days to flowering did not differ between inbred and outcross plants, inbred plants produced fewer flowers. Finally, cumulative fitness, an integrated measure of germination, survivorship and reproduction, was significantly less for inbred individuals (Tables 2 and 3). These differences between self and outcross progeny lead to significant inbreeding depression for days to germination, leaf size, survivorship to flowering, percentage flowering, final biomass, and cumulative fitness (Figure 1).

Environmental and genetic factors reflected by year, population, and maternal plant also contributed to the expression of offspring traits. The number of days to germination, rosette leaf size, flowering date, percentage flowering, flower number, and cumulative fitness all 
Table 2 Means (SE) of outcross and self offspring of plants from three populations of C. americana. Means are presented for (a) individual- or (b) family-level traits. (see Table 3 for analysis)

\begin{tabular}{|c|c|c|c|c|c|c|}
\hline & \multicolumn{2}{|c|}{ River } & \multicolumn{2}{|c|}{ Mtn613 } & \multicolumn{2}{|c|}{$M t n 700$} \\
\hline & Outcross & Self & Outcross & Self & Outcross & Self \\
\hline \multicolumn{7}{|l|}{ (a) } \\
\hline Seed number & $43.4(3.3)$ & $38.1(1.8)$ & $29.2(3.3)$ & $29.3(5.5)$ & $35.1(3.0)$ & $34.1(3.1)$ \\
\hline Seed mass (mg) & $0.251(0.012)$ & $0.242(0.011)$ & $0.283(0.013)$ & $0.264(0.008)$ & $0.279(0.011)$ & $0.276(0.010)$ \\
\hline Days to germinate & $16.0(0.9)$ & $18.3(1.1)$ & $19.1(1.2)$ & $20.7(1.2)$ & $13.9(0.5)$ & $14.8(0.6)$ \\
\hline Leaf length $(\mathrm{mm})$ & $19.6(0.4)$ & $16.2(0.5)$ & $18.6(0.5)$ & $15.7(0.7)$ & $13.2(0.3)$ & $11.8(0.4)$ \\
\hline Biomass $(\mathrm{g})$ & $4.29(0.08)$ & $3.96(0.15)$ & $4.08(0.16)$ & $3.26(0.21)$ & $4.60(0.18)$ & $3.41(0.28)$ \\
\hline Days to flower & $101.3(2.5)$ & $104.4(3.0)$ & $118.8(3.1)$ & $115.4(4.8)$ & $176.0(1.2)$ & $178.33(2.2)$ \\
\hline Flower number & $148.8(8.5)$ & $132.6(10.5)$ & $100.4(12.6)$ & $88.3(19.5)$ & $65.5(4.5)$ & $51.7(7.8)$ \\
\hline \multicolumn{7}{|l|}{ (b) } \\
\hline Germination (\%) & $88.0(2.7)$ & $86.4(2.1)$ & $81.2(3.3)$ & $79.7(4.8)$ & $82.0(3.2)$ & $79.5(5.4)$ \\
\hline Survivorship (\%) & $91.9(3.1)$ & $83.3(3.1)$ & $93.1(2.7)$ & $84.9(2.8)$ & $95.0(1.8)$ & $85.6(3.8)$ \\
\hline Flowering (\%) & $90.5(2.4)$ & $86.1(5.0)$ & $76.3(4.3)$ & $67.8(7.3)$ & $70.0(3.8)$ & $54.7(5.9)$ \\
\hline Cumulative fitness & $107.0(8.8)$ & $81.9(9.7)$ & $57.4(12.0)$ & $49.2(14.0)$ & $39.5(4.4)$ & $23.2(4.5)$ \\
\hline
\end{tabular}

Table 3 Comparison of outcross and self offspring of plants from three populations of C. americana. Year is included as a blocking factor. Analyses were conducted on individual plants (a) or family means (b).

\begin{tabular}{|c|c|c|c|c|c|c|c|}
\hline & $\begin{array}{l}\text { Year } \\
F\end{array}$ & $\begin{array}{c}\text { Pop (year) } \\
F\end{array}$ & $\begin{array}{c}\text { Plant (year, pop) } \\
Z\end{array}$ & $\begin{array}{c}\text { Cross-type } \\
F\end{array}$ & $\begin{array}{c}\text { Year }{ }^{*} \text { cross } \\
F\end{array}$ & $\begin{array}{c}\text { Pop }{ }_{F}^{*} \text { cross } \\
F\end{array}$ & $\begin{array}{c}\text { Plant }{ }^{*} \text { cross } \\
Z\end{array}$ \\
\hline \multicolumn{8}{|l|}{ (a) } \\
\hline Seed number & 0.02 & $3.70+$ & $4.32^{* * *}$ & $5.35^{*}$ & 2.02 & 1.43 & 0 \\
\hline Seed mass & 1.86 & $3.36+$ & $4.28^{* * *}$ & $3.13+$ & 1.01 & 0.18 & $3.12^{* * *}$ \\
\hline Days to germinate & $25.09^{* * * *}$ & $7.00^{*}$ & $3.55^{* * *}$ & $17.50^{* * *}$ & 0.18 & 0.87 & 0 \\
\hline Leaf length & $152.52^{* * *}$ & 2.16 & $3.20^{* * *}$ & $111.26^{* * *}$ & $14.16^{* * *}$ & 0.82 & 0 \\
\hline Biomass & 0.12 & $3.04+$ & $1.88^{*}$ & $48.55^{* * *}$ & $8.28^{* *}$ & 2.15 & $1.76^{*}$ \\
\hline Days to flower & $758.51^{* * *}$ & $17.37^{* * *}$ & $2.98^{* *}$ & 0.02 & 0.35 & $6.82^{*}$ & 0.74 \\
\hline Flower number & $40.35^{* * *}$ & $10.00^{* *}$ & $2.71^{* *}$ & $4.02^{*}$ & 0.05 & 0.12 & 0.56 \\
\hline \multicolumn{8}{|l|}{ (b) } \\
\hline Germination (\%) & 0.02 & 1.25 & $2.03^{*}$ & 0.02 & 0.45 & 0.13 & \\
\hline Survivorship (\%) & 1.67 & 0.05 & 1.20 & $16.23^{* * *}$ & 0.03 & 0.00 & \\
\hline Flowering $(\%)$ & $12.78^{* * *}$ & $7.91^{* *}$ & $2.57^{* *}$ & $6.54^{*}$ & 2.06 & 0.47 & \\
\hline Cumulative fitness & $28.13^{* * *}$ & $13.04^{* * *}$ & $3.42^{* * *}$ & $16.23^{* * *}$ & 0.00 & 2.62 & \\
\hline
\end{tabular}

F-values $(\mathrm{df}=1,40-47)$ and Z-values from mixed-model ANOVA are presented. $+0.05<P<0.1 ;{ }^{*} P<0.05 ;{ }^{* *} P<0.01 ;{ }^{* * *} P<0.001$.

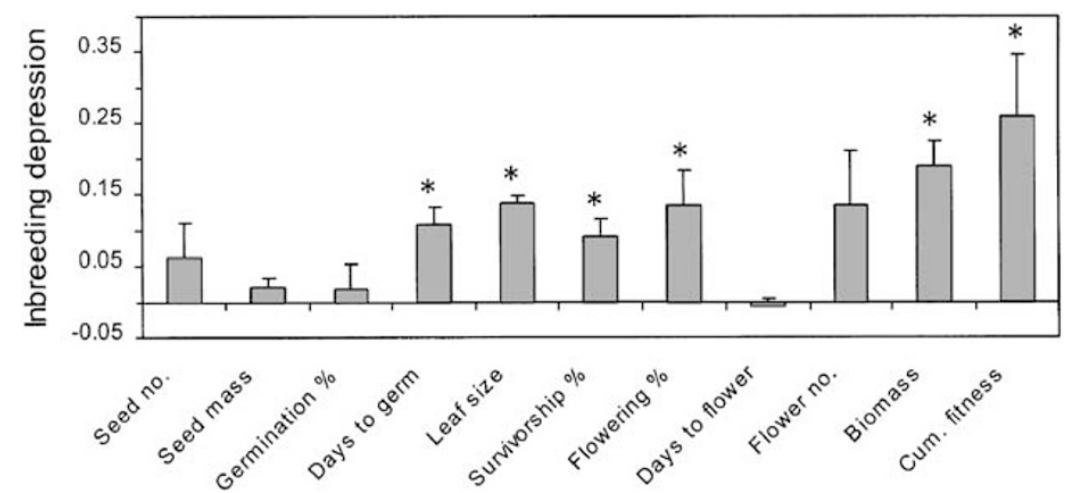

Figure 1 Inbreeding depression estimates (SE) for C. americana averaged across families and populations. If outcross progeny outperform self progeny, values are $>0$ ( ${ }^{*}$ indicates significant deviation from zero following a sequential Bonferroni on $t$-test values).

differed between the 2 years of study (Table 3). This effect may be because of differences in the experimental design between years (ie germination on filter paper vs soil), annual weather conditions, and population effects
(Mtn700 vs Mtn613 and River). The population factor tests whether there are differences between the Mtn613 and River populations grown during the first year. These populations differed for timing of germination and 
flowering, percentage flowering, flower number, and cumulative fitness (Table 3). Finally, variation among offspring of different maternal plants was found for all traits except survivorship from germination to flowering (Table 3).

Inspite of the contribution of year, population, and maternal plant to offspring trait expression, the effect of the crossing treatment varied little across these environmental and genetic blocking factors. The reduction of leaf length and biomass as a consequence of selfing differed between years of the study with inbreeding depression being greater for leaf length but smaller for biomass during the first year (Table 2). However, inbreeding depression for both characters was significantly different from zero in both years. Although there was no overall inbreeding depression for flowering date, the effects of cross-type differed in direction between the Mtn613 and River populations (Table 3). Inbred plants flowered later in the River population $(\delta=-0.03)$ but earlier in the Mtn613 population ( $\delta=0.04$, Table 2$)$, but in neither $\delta$ differed significantly from zero. Therefore, although there were significant differences in performance between the cross types across years for leaf length and biomass, and between populations for number of days to flower, little information is lost by pooling $\delta$ across populations. The expression of inbreeding depression differed between individuals within populations for seed mass and biomass indicating potential genetic variation for inbreeding depression in these traits (Table 3).

\section{Discussion}

\section{Outcrossing rate}

C. americana is almost completely outcrossing. This high level of outcrossing is surprising since plants appear to be fully self-compatible and there is no significant inbreeding depression for fruit or seed production. An outcrossing rate of near unity is also unexpected in the light of pollinator behavior. Bumblebees facilitate selffertilization by moving from male-phase to female-phase flowers within plants. This opportunity for geitonogamy increases with display size in C. americana (Galloway et al, 2002). Although large floral displays are found in the population for which the outcrossing rate was determined, display size is log-normally distributed with many plants having small displays (Galloway et al, 2002). In small floral displays protandry may effectively limit self-pollination. However, it seems unlikely that protandry alone can account for the high outcrossing rate given the potential for within-plant pollen movement, even in small displays.

An alternative explanation for the high outcrossing rate is that outcross pollen has a siring advantage over self-pollen when both compete for fertilization opportunities. Postpollination processes may occur in selfcompatible taxa such that self-fertilization is less than the fraction of self pollen on the stigma (ie cryptic selfincompatibility; Cruzan and Barrett, 1996). In C. americana pollinator visits to flowers are frequent, averaging 15 visits/h in the Mtn700 population (Evanhoe and Galloway, 2002). Multiple visits in short succession combined with pollen carryover mean that flowers may receive self and outcross pollen nearly synchro- nously. In addition, C. americana flowers are fully pollinated within a few hours of the initiation of female phase (Evanhoe and Galloway, 2002), therefore competition between self and outcross pollen for fertilization opportunities is likely. In summary, the high frequency of outcrossing of $C$. americana and other polyploid species (MacDonald and Lieffers, 1991; Husband and Schemske, 1997; Petit et al, 1997; Inoue et al, 1998; Miller and Venable, 2000) suggests selection for mechanisms that enhance outcrossing following polyploid establishment.

\section{Inbreeding depression}

Although there is little inbreeding depression for seed production, increased inbreeding depression in later life stages could select for mechanisms that enhance outcrossing. Like seed production, there was no inbreeding depression for seed mass and percentage germination. However, there was significant inbreeding depression for timing of germination, rosette size, survivorship to flowering, percent flowering, and final biomass. These traits, combined with a trend toward the production of fewer flowers on inbred plants, resulted in a $26 \%$ reduction in cumulative fitness of inbred plants relative to outcrossed individuals.

Reduced inbreeding depression for seed and germination traits and significant, although not large, inbreeding depression for later life characters may be typical for species that are outcrossing but self-compatible. Predominately outcrossing angiosperms often express substantial inbreeding depression in both early and later life traits (Husband and Schemske, 1996). In contrast, habitually selfing species typically express limited inbreeding depression because of the removal of recessive lethals by selection (Lande and Schemske, 1985). This reduced inbreeding depression is particularly marked early in the life cycle (Husband and Schemske, 1996), suggesting lethals are often expressed early in development. The presence of little early life-cycle inbreeding depression in highly outcrossing C. americana may reflect the bottleneck of $C$. americana's establishment. Since successful crosses between ploidy levels are limited, early-stage polyploids are expected to experience very small effective population sizes and substantial inbreeding. During this bottleneck, recessive lethals are likely to be purged by selection. In addition, ongoing fluctuations in C. americana's population size (see below) and the founding of new populations may result in periods of inbreeding sufficient to reduce early acting lethals. However, the fairly high level of allelic polymorphism observed argues against this as the sole explanation for low levels of inbreeding depression.

Alternatively, estimates of inbreeding depression in C. americana may be less than predominately outcrossing angiosperms because it is an autotetraploid. Following one generation of selfing, homozygosity increases by $50 \%$ at a diploid heterozygous locus. In contrast, in an autotetraploid with tetrasomic inheritance, homozygosity is expected to increase at less than half that rate (Bever and Felber, 1992). Since most inbreeding depression is because of the expression of recessive or partially recessive deleterious alleles (Dudash and Carr, 1998), inbreeding depression in polyploids is expected to be modest relative to diploids (eg Husband and Schemske, 
1997). The specific magnitude of the reduction in inbreeding depression relative to diploids is influenced by the degree of dominance (Ronfort, 1999), the amount of double reduction (Butruille and Boiteux, 2000), and the loss of complementary gene interactions (Bingham et al, 1994).

The association between inbreeding depression and mating system in tetraploid angiosperms mirrors patterns found in diploids. Modest inbreeding depression has been found for cumulative fitness in selfing allotetraploids (Johnston and Schoen, 1996; Belaoussoff and Shore, 1995), while primarily outcrossing allo- and autotetraploids exhibit greater inbreeding depression (Husband and Schemske, 1997; Kephart et al, 1999; Vogler et al, 1999; Dudash and Fenster, 2001). Based on this pattern and C. americana's highly outcrossing mating system, we would expect greater inbreeding depression than was observed. More studies of inbreeding depression in autopolyploid angiosperms are needed to evaluate whether this result is general.

Selection for mechanisms that enhance outcrossing is expected to be strong in species with substantial inbreeding depression. It is surprising that the moderate fitness differences observed between self and outcross individuals in C. americana would provide a sufficient selective force to drive the evolution of outcrossing mechanisms. However, plants in the present study were watered, fertilized, and grown under noncompetitive conditions. In natural C. americana populations, there is a greater opportunity for the expression of inbreeding depression because fewer individuals survive and there is a greater variance in flower production than in the greenhouse (Galloway and Etterson, unpublished). Studies in other species report greater inbreeding depression in natural environments (eg Dudash, 1990), supporting a possible underestimate in the current study.

C. americana's high outcrossing rate, self-compatibility, and limited inbreeding depression provide evidence for a flexible mating system. The high outcrossing rate may have been favored by selection to avoid fitness loss because of self-fertilization. In response to this selection, a mechanism to enhance outcrossing other than strict self-incompatibility may have evolved because tetraploidy reduces self-incompatibility (de Nettancourt, 2000). Alternatively, reproductive assurance could favor flexible mechanisms to enhance outcrossing. For example, reduction in self-incompatibility with flower age in congener $C$. rapunculoides provides a similarly flexible mating system (Vogler et al, 1998). C. americana is frequently found in small populations $(<50)$ and isolated individuals are not uncommon (Galloway, unpublished). In addition, it typically grows in disturbed areas (eg steep hillsides), has small seeds, and is one of the few monocarpic species in its community. These life history characteristics suggest that small population size may occur frequently and could have selected for mechanisms to reduce inbreeding when mating opportunities are plentiful but maintain reproductive success when mates are limited.

\section{Acknowledgements}

We thank E Miller for help with pollinations and seed germination; the Mountain Lake Biological Station for logistical support; $M$ Dudash for comments on a previous version of the manuscript; and the National Science Foundation (DEB-9752947, DEB-9974126 to LFG) and a UVA FEST award for financial support.

\section{References}

Belaoussoff S, Shore JS (1995). Floral correlates and fitness consequences of mating-system variation in Turnera ulmifolia. Evolution 49: 545-556.

Bever JD, Felber F (1992). The theoretical population genetics of autopolyploidy. In: Antonovics J, Futuyma D (eds) Oxford Surveys in Evolutionary Biology, Oxford University Press: New York. Vol 8, pp 185-217.

Bingham ET, Groose RW, Woodfield DR, Kidwell KK (1994). Complementary gene interactions in alfalfa are greater in autotetraploids than diploids. Crop Sci 34: 823-829.

Burton TL, Husband BC (2000). Fitness differences among diploids, tetraploids, and their triploid progeny in Chamerion angustifolium: mechanisms of inviability and implications for polyploid evolution. Evolution 54: 1182-1191.

Busbice TH, Wilsie CP (1966). Inbreeding depression and heterosis in autotetraploids with application to Medicago sativa L. Euphytica 15: 52-67.

Butruille DV, Boiteux LS (2000). Selection-mutation balance in polysomic tetraploids: impact of double reduction and gametophytic selection on the frequency of subchromosomal localization of deleterious mutations. Proc Natl Acad Sci USA 97: 6608-6613.

Cook LM, Soltis PS (1999). Mating systems of diploid and allotetraploid populations of Tragopogon (Asteraceae). I. Natural populations. Heredity 82: 237-244.

Cruzan MB, Barrett SCH (1996). Postpollination mechanisms influencing mating patterns and fecundity: an example from Eichhornia paniculata. Am Nat 147: 576-598.

de Nettancourt D (2000). Incompatibility and Incongruity in Wild and Cultivated Plants, Springer-Verlag: Berlin.

Dudash MR (1990). Relative fitness of selfed and outcrossed progeny in a self-compatible, protandrous species, Sabatia angularis L. (Gentianaceae): a comparison in three environments. Evolution 44: 1129-1139.

Dudash MR, Carr DE (1998). Genetics underlying inbreeding depression in Mimulus with contrasting mating systems. Nature 393: 682-684.

Dudash MR, Fenster CB (2001). The role of breeding system and inbreeding depression in the maintenance of an outcrossing mating strategy in Silene virginica (Caryophyllaceae). Am J Bot 88: 1953-1959.

Evanhoe L, Galloway LF (2002). Floral longevity in Campanula americana (Campanulaceae): a comparison of morphological and functional gender phases. Am J Bot 89: 611-615.

Gadella TWJ (1964). Cytotaxonomic studies in the genus Campanula. Wentia 11: 1-104.

Gairdner AE (1926). Campanula persicifolia and its tetraploid form, 'Telham beauty.' J Genet 16: 341-351.

Galloway LF, Cirigliano T, Gremski K (2002). The contribution of display size and dichogamy to potential geitonogamy in Campanula americana. Int J Plant Sci 163: 133-139.

Husband BC, Schemske DW (1996). Evolution of the magnitude and timing of inbreeding depression in plants. Evolution 50: 54-70.

Husband BC, Schemske DW (1997). The effect of inbreeding in diploid and tetraploid populations of Epilobium angustifolium (Onagraceae): implications for the genetic basis of inbreeding depression. Evolution 51: 737-746.

Inoue K, Masuda M, Maki M (1998). Inbreeding depression and outcrossing rate in the endangered autotetraploid plant Aster kantoensis (Asteraceae). J Heredity 89: 559-562.

Johnston MO, Schoen DJ (1996). Correlated evolution of selffertilization and inbreeding depression: an empirical study of nine populations of Amsinckia (Boraginaceae). Evolution 50: 1478-1491. 
Kephart SR, Brown E, Hall J (1999). Inbreeding depression and partial selfing: evolutionary implications of mixed-mating in a coastal endemic, Silene douglasii var. oraria (Caryophyllaceae). Heredity 82: 543-554.

Lande R, Schemske DW (1985). The evolution of self fertilization and inbreeding depression in plants. I. Genetic models. Evolution 39: 24-40.

Macdonald SE, Lieffers VJ (1991). Population variation, outcrossing, and colonization of disturbed areas by Calamagrostis canadensis: evidence from allozyme analysis. Am J Bot 78: 1123-1129.

Maki M (1993). Outcrossing and fecundity advantage of females in gynodioecious Chionographis japonica var. kurohimensis (Liliaceae). Am J Bot 80: 629-634.

Miller JS, Venable DL (2000). Polyploidy and the evolution of gender dimorphism in plants. Science 289: 2335-2338.

Murawski DA, Fleming TH, Ritland K, Hamrick JL (1994). Mating system of Pachycereus pringlei: an autotetraploid cactus. Heredity 72: 86-94.

Petit C, Lesbros P, Ge XJ, Thompson JD (1997). Variation in flowering phenology and selfing rate across a contact zone between diploid and tetraploid Arrhenatherum elatius (Poaceae). Heredity 79: 31-40.

Ritland K (1990). A series of FORTRAN computer programs for estimating plant mating systems. J Heredity 81: 235-237.

Ronfort J (1999). The mutation load under tetrasomic inheritance and its consequences for the evolution of the selfing rate in autotetraploid species. Genet Res 74: 31-42.

Soltis DE, Haufler CH, Darrow DC, Gastony GJ (1983). Starch gel electrophoresis of ferns: a compilation of grinding buffers, gel and electrode buffers, and staining schedules. Am Fern J 73: 9-27.

Vogler DW, Das C, Stephenson AG (1998). Phenotypic plasticity in the expression of self-incompatibility in Campanula rapunculoides. Heredity 81: 546-555.

Vogler DW, Filmore K, Stephenson AG (1999). Inbreeding depression in Campanula rapunculoides L. I. A comparison of inbreeding depression in plants derived from strong and weak self-incompatibility phenotypes. J Evol Biol 12: 483-494.

Wendel JF, Parks CR (1982). Genetic control of isozyme variation in Camellia japonica L. J Heredity 73: 197-204. 